\title{
UJI MODEL FISIK BANGUNAN PELIMPAH BENDUNGAN SAKA GILAS DENGAN SKALA 1:50
}

\author{
Rahmah Dara Lufira ${ }^{1}$, Muhammad Amar Sajali ${ }^{1}$, Suwanto Marsudi ${ }^{1}$, Very Dermawan ${ }^{1}$ \\ 1Dosen Jurusan Teknik Pengairan Universitas Brawijaya \\ e-mails: rahmahdara@ub.ac.id
}

\begin{abstract}
Abstrak: Uji model fisik hidrolika yang dilakukan di laboratorium dimaksudkan untuk mengetahui perilaku hidrolika aliran pada bangunan hidrolik yang diujikan. Tujuan uji model bangunan pelimpah Bendungan Sakagilas ini adalah untuk mengetahui profil aliran yang terjadi pada sistem pelimpah, meliputi kedalaman aliran, kecepatan, tekanan aliran air dan bilangan Froude. Juga untuk mengetahui unjuk kerja hidrolik desain pelimpah, saluran transisi, saluran peluncur, kolam olak/peredm energi, dan saluran hilir (escape channel). Tekanan akibat aliran air yang terjadi pada sistem pelimpah (ambang pelimpah, saluran transisi, dan terutama saluran peluncur) diukur dan dianalisa untuk mengetahui kondisi keamanan bangunan terhadap bahaya kavitasi dan aliran getar. Pelimpah pada Bendungan Saka Gilas merupakan side channel spillway (Fixed+Gated) dengan mercu pelimpah berbentuk Ogee. Bentuk pelimpahnya adalah melingkar seperempat lingkaran $\left(45^{\circ}\right)$. Pengamatan awal pada uji model fisik dilakukan pada kondisi Original Design, yang apabila terdapat perilaku hidrolika aliran yang tidak baik, maka akan dilakukan modifikasi desain. Modifikasi desain dimaksudkan untuk mendapatkan perilaku hidrolika aliran terbaik, sesuai standar kriteria desain sistem bangunan pelimpah.
\end{abstract}

Key words: Pelimpah Samping, Hidrolika, Model Fisik Hidrolik

Abstract: The physical hydraulic model carried out in the laboratory is intended to determine the hydraulic behavior of the flow in hydraulic structures. The aim of Hydraulic model test of Sakagilas Dam spillway is to determine the flow profile that occurs in spillway system, including flow depth, velocity, water flow pressure, and Froude numbers. Also to find out the hydraulic performance of side spillway design, transition channel, chute way channel, energy dissipator, and escape channel. Investigation of water flow pressure in the spillway system (side channel spillway, transition channel, and especially chute way channel) was measured and analyzed to determine the condition of structure safety against cavitation and vibration flow.

The spillway of Saka Gilas Dam is a side channel spillway (Fixed+Gated) with an Ogee spillway. The shape of the side spillway is circular quarter circle $\left(45^{\circ}\right)$. Preliminary observations on the physical model test are carried out under the condition of Original Design, which if there is a poor flow hydraulic behavior, design modifications will be made. The design modification is intended to get the best flow hydraulic behavior, according to the standard design criteria for the side channel spillway system.

Key words: Side Channel Spillway, Hydraulics, Physical Hydraulic Model 
Bendungan adalah sebuah bangunan melintang sungai yang berfungsi untuk menahan dan atau menampung air sehingga terbentuk waduk. Waduk dapat dimanfaatkan untuk irigasi, pembangkit listrik tenaga air (PLTA), pengendali banjir, air bersih, ataupun sarana rekreasi. Bendungan memiliki beberapa bagian struktur bangunan, antara lain tubuh bendungan, intake, sistem pelimpah dan bangunan pelengkap lainnya (Sosrodarsono, 1989).

Seringkali kondisi aliran pada sistem pelimpah bendungan, yang dimulai dari saluran pengarah (approach channel) sampai saluran pengarah hilir (escape channel) yang telah direncanakan belum dan atau tidak dapat teridentifikasi dengan baik melalui pendekatan perhitungan analitik dan model matematik. Oleh karena itu, perlu dilakukan pemecahan masalah dengan melakukan pengujian terhadap dimensidimensi bangunan yang telah direncanakan dalam bentuk uji model fisik hidrolika. Uji model fisik ini digunakan untuk peninjauan unjuk kerja keseluruhan bangunan yang telah direncanakan, terutama perilaku hidrolika aliran pada sistem bangunan pelimpah. Sehingga dapat diperoleh tingkat keyakinan yang tinggi terhadap keberhasilan dan keamanan desain, mengingat konstruksi bendungan merupakan bangunan yang sangat penting dan mempunyai resiko tinggi dari segi finansial maupun sosial (Triatmojo, 1995).

Penelitian ini merupakan uji model fisik hidrolik Bendungan Saka Gilas di Kabupaten Ogan Komering Ulu (OKU) Selatan Provinsi Sumatera Selatan. Bendungan ini diharapkan dapat memenuhi kebutuhan air irigasi, air baku, pembangkit listrik tenaga air (PLTA), dan pengendalian banjir di kabupaten Ogan Komering Ulu Selatan.

Maksud dari pelaksanaan penelitian uji model fisik hidrolik ini adalah mempelajari perilaku hidrolika aliran pada sistem bangunan pelimpah serta fenomena lainnya yang belum diketahui terutama pada bagian hilir bangunan peredam energi.

\section{BAHAN DAN METODE Peralatan Pengujian}

Untuk mendukung pelaksanaan uji model tes di laboratorium, fasilitas pengujian yang akan digunakan di Laboratorium terdiri dari peralatan sebagai berikut:
1. 6 unit pompa listrik dan 2 unit pompa diesel (4 unit pompa listrik kapasitas 10 l/det per pompa dan 2 unit dengan kapasitas 40 1/det per pompa, 2 unit pompa diesel dengan kapasitas 40 1/det per pompa).

2. Tandon air bawah tanah (ground reservoir) dengan kapasitas $1000 \mathrm{~m}^{3}$ dan tandon atas $100 \mathrm{~m}^{3}$.

3. Sistem sirkulasi air antara unit pompa tandon air dan sistem model tes.

4. Cetakan material untuk pekerjaan kayu dan pasangan untuk membentuk model fisik hidrolik sebangun dengan prototipenya.

5. Instrumentasi pengukuran di laboratorium: current meter, meteran taraf (point gauge), piezometer, dan pengukur debit Rechbox.

6. Instrumentasi pengukuran levelling untuk pencapaian posisi elevasi yang tepat dari model fisik, berupa Waterpass dan Theodolit.

7. 2 Unit HT untuk keperluan komunikasi pengoperasian pompa saat uji model tes.

\section{Sirkulasi Air di Laboratorium}

Ruangan yang digunakan dalam Uji Model Fisik Hidrolik Waduk Saka Gilas seluas \pm 1000 $\mathrm{m}^{2}$. Sirkulasi air di model tes adalah siklus tertutup dengan sumber air berasal dari sumber air tanah dan air PDAM. Dengan air yang jernih diharapkan dapat dilakukan pengamatan fenomena aliran yang lebih teliti.

Pembuatan konstruksi model tes dilakukan dengan sangat teliti baik dari segi ukuran, bentuk dan elevasi bangunannya, yang model ini dibuat dengan mengacu gambar desain prototipe desain asli (original design) dari hasil pekerjaan konsultan perencana pada pekerjaan Detail Desain Waduk Saka Gilas. Pembuatan konstruksi model tes dilakukan secara segmental dan betahap antara komponen satu dengan komponen yang lainnya, Kemudian di rakit dan dilakukan setting menjadi satu kesatuan sesuai dengan bentuk prototipenya.

\section{Debit Pengaliran}

Bangunan ukur debit tipe Rechbox digunakan sebagai alat ukur debit untuk mengendalikan secara bersama-sama dengan pintu pengatur spillout supaya diperoleh debit ke daerah tampungan waduk model tes sama dengan 
debit outflow rencana pengujian. Kurva liku debit

Rechbox dapat dilihat pada Gambar 1.

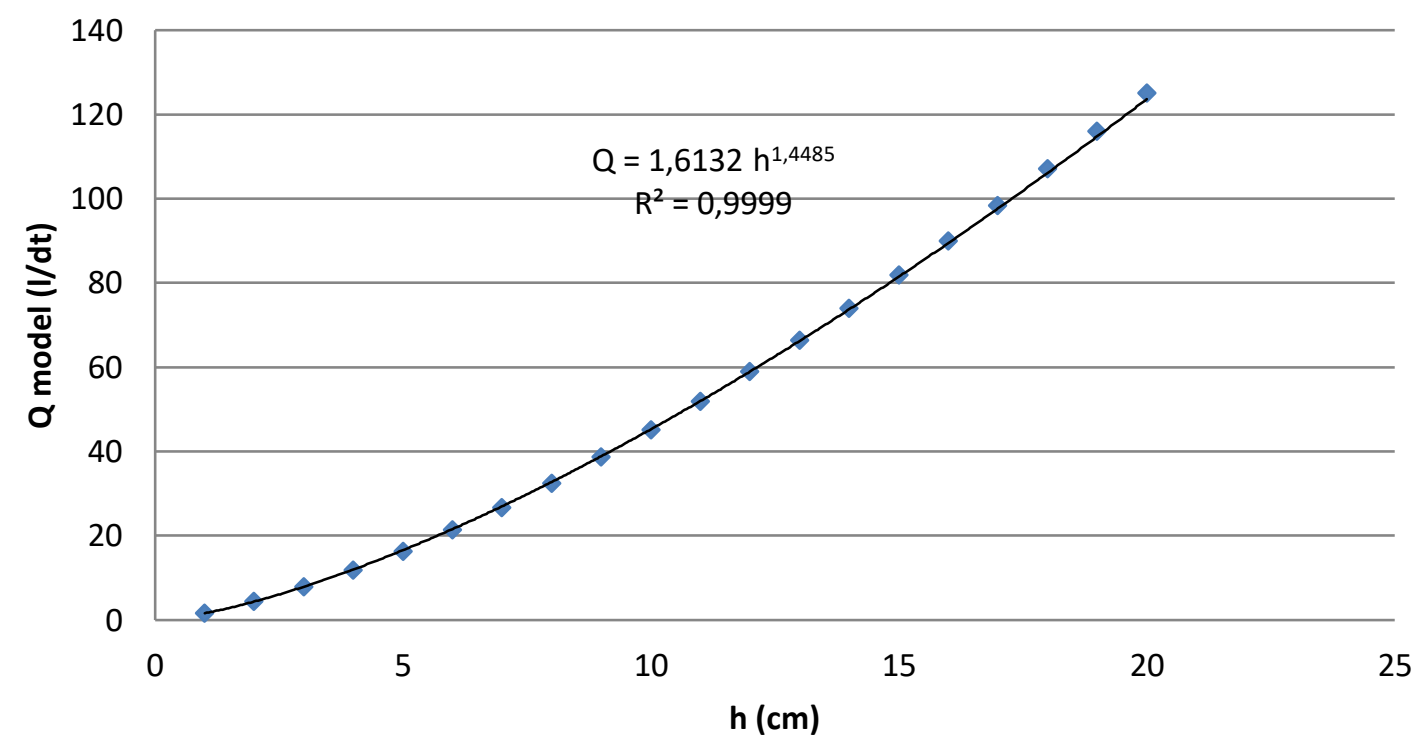

Gambar. 1. Kurva liku debit Rechbox

\section{Pemilihan dan Penetapan Skala Model}

Pemilihan skala uji model fisik hidrolik yang cocok tergantung pada tipe sistem fluida yang akan distudi, dan bergantung pada ruang yang tersedia untuk membuat model.

Apabila hubungan antar skala dan kesebangunan telah dipenuhi (sebangun geometris, kinematis, dan dinamis), maka tingkat ketelitian perlu diperhatikan sehubungan dengan besarnya nilai skala yang digunakan.

Skala pada uji model fisik hidrolik pelimpah Bendungan Sakagilas adalah skala 1 : 50 . Pengaliran outflow debit banjir rancangan 2 tahun (Q2) melalui pelimpah diperoleh tingkat kesalahan kedalaman aliran di atas pelimpah $2,38 \% \quad(\mathrm{KR}<10 \%)$ atau tingkat ketelitian $97,62 \%$.

\section{Pengamatan Pola Aliran}

Setelah model tes selesai di bangun di Laboratorium, langkah selanjutnya adalah melakukan verifikasi dimensi dan presisi elevasi tiap komponen model tes yang akan di teliti serta melakukan unjuk kerja awal untuk memastikan kinerja tiap komponen model tes berfungsi dengan baik.

Kegiatan pada langkah ini merupakan kegiatan untuk melihat secara visual pola aliran yang terjadi pada bagian-bagian pelimpah mulai dari:

1. Pola aliran di waduk pada bagian inlet pelimpah.

2. Pola aliran di pada sistem pelimpah.

3. Pola aliran pada bagian saluran transisi, saluran peluncur dan peredam energi.

4. Pola aliran pada alur sungai di hilir peredam energi.

\section{HASIL DAN PEMBAHASAN Model Seri 0}

Model Tes Seri 0 (original design) dapat dijelaskan hasil pengamatannya sebagai berikut:

a. Kolam Tampungan Waduk
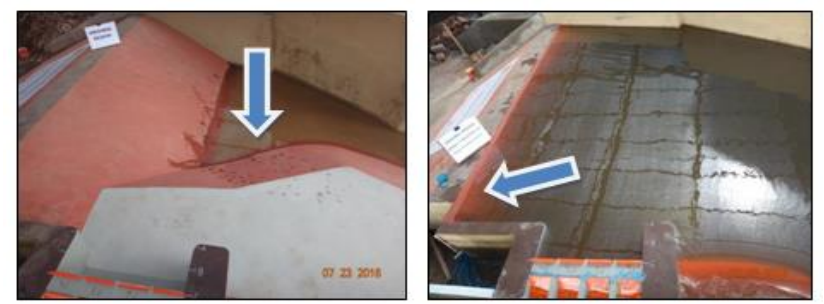

Gambar 2.Kondisi Daerah Tampungan Waduk di Model Fisik Hidrolik.

Daerah tampungan model fisik mampu memberikan kondisi tampungan yang tenang dan sesuai dengan kondisi tampungan waduk secara 
umum. Namun pada saat pengaliran debit dengan kala ulang 200 tahun (Q200=1508,01 $\mathrm{m}^{3} / \mathrm{dt}$ ) sudah terjadi overtopping pada bendungan utama.

\section{b. Saluran Pengarah (Approach Channel)}

Bagian saluran ini sebagai penuntun dan pengarah aliran agar aliran tersebut senantiasa dalam kondisi hidrolika yang baik. Kecepatan masuk aliran air <4 m/det, karena apabila melebihi kecepatan tersebut, maka aliran akan bersifat helisoidal, kapasitas pengalirannya menurun, juga akan mengakibatkan beban hidrodinamis pada sistem bangunan pelimpah (Sosrodarsono, 1989).
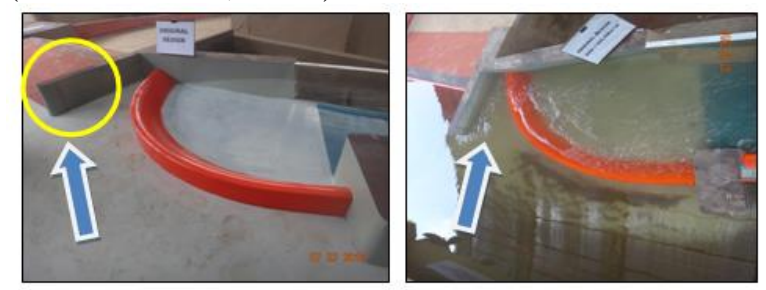

Gambar 3.Kondisi Saluran Pengarah di Model Fisik Hidrolik.

Kondisi pengaliran di saluran pengarah pada pelimpah menggambarkan kondisi yang baik, relatif tenang. Namun keberadaan pilar yang berposisi tegak lurus serta berjari-jari memberikan alur pemasukan aliran yang kurang halus, masih terindikasi adanya penciptaan olakan atau bahkan pusaran aliran di dekat batas tebing saluran pengarah.

\section{c. Ambang Pelimpah}

Pengaliran debit kala ulang 200 tahun sudah terjadi overtopping pada bendungan utama. Untuk mengatasi keadaan tersebut, maka pada bagian apron hilir pelimpah perlu di lakukan penurunan dasar saluran, sehingga apabila dialirkan debit yang lebih besar tidak akan terjadi overtopping pada bendungan.
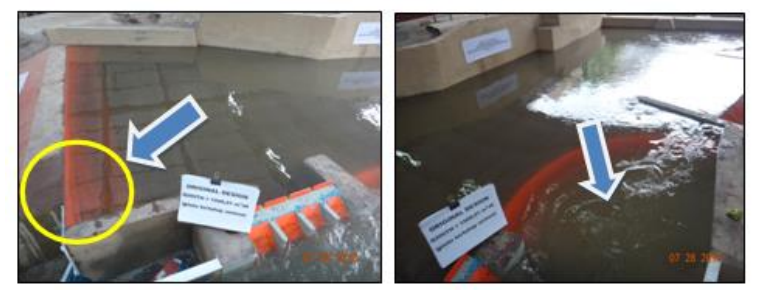

Gambar 4.Kondisi Pelimpah di Model Fisik Hidrolik.

Selain itu terjadi pula pusaran pada hilir pelimpah. Apabila terjadi secara terus menerus, maka akan merusak dinding samping yang berada di depan hilir pelimpah. Oleh karena itu selain dilakukan penurunan dasar juga diperlukan peredam energi pada dasar hilir pelimpah.

\section{d. Pelimpah Darurat (Emergency Spillway)}

Pelimpah darurat merupakan pelimpah yang dipergunakan untuk melewatkan debit banjir yang datang. Aliran air akan melewati pelimpah darurat tersebut apabila pelimpah dan pintu sudah tidak mampu lagi menampung debit yang lewat. Pada seri 0 dengan kondisi pintu tutup, pengaliran debit dengan kala ulang 50 tahun (Q50=1364,93 $\mathrm{m}^{3} / \mathrm{dt}$ ) aliran air sudah melewati pelimpah darurat.

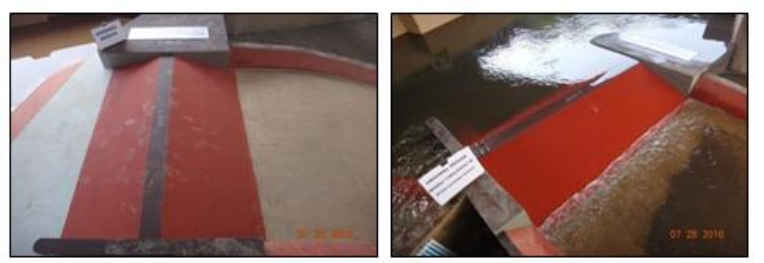

Gambar 5.Kondisi Pelimpah Darurat di Model Fisik Hidrolik

\section{e. Saluran Samping (Side Channel)}

Aliran pada kondisi debit banjir tidak boleh menenggelamkan ambang pada saluran pengatur, sehingga saluran samping dibuat cukup rendah terhadap ambang tersebut. Perbedaan muka air di hulu dan hilir ambang pelimpah samping tidak kurang dari $2 / 3$ kali tinggi air di atas mercu ambang pelimpah tersebut (Bureau of Reclamation, 1987). Pada kondisi ideal, elevasi permukaan air di hilir ambang pelimpah samping diusahakan hampir sama dengan elevasi mercu ambang pelimpah tersebut.

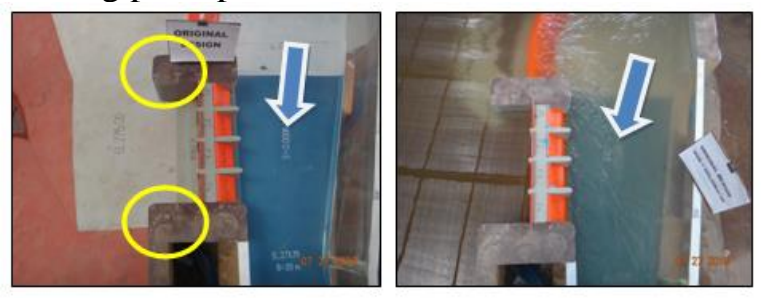

Gambar 6.Kondisi Saluran Samping di Model Fisik Hidrolik.

Kondisi pengaliran di pintu pelimpah menggambarkan kondisi yang baik dan relatif tenang. Namun keberadaan pilar pada pintu tersebut memberikan alur pemasukan aliran yang kurang halus, sehingga pilar tersebut dibuat lebih melengkung dengan jari-jari yang lebih besar dari 
sebelumnya. Dengan memperbesar jari-jari tersebut juga akan mengurangi koefisien gesekan yang terjadi akibat adanya pilar.

\section{f. Saluran Transisi (Transition Channel)}

Saluran transisi merupakan saluran penghubung antara saluran samping dengan saluran peluncur. Saluran transisi direncanakan agar debit banjir rencana yang disalurkan tidak menimbulkan aliran balik (backwater) di bagian hilir saluran samping dan memberikan kondisi yang paling menguntungkan, baik pada aliran di dalam saluran transisi tersebut maupun pada aliran permulaan yang akan menuju saluran peluncur.

Mengingat saluran transisi ini sangat besar pengaruhnya terhadap regim aliran di dalam saluran peluncur dan berfungsi sebgai pengatur aliran pada debit banjir abnormal, maka bentuk saluran ini direncanakan dengan sangat hati-hati. Untuk menghindari aliran helisoidal di dalam saluran ini, maka perlu diusahakan agar bentuknya simetris terutama pada penampang lintang dan tampak atasnya.

Pada saluran transisi ini, terindikasi adanya aliran yang cepat dan tidak tercipta aliran tenang di sepanjang saluran samping sampai saluran transisi hilir. Untuk mengatasi masalah ini diusulkan untuk dibuat endsill di section akhir saluran transisi 2. Hal ini dimaksudkan untuk memperbaiki profil aliran di sepanjang saluran samping dan saluran transisi.
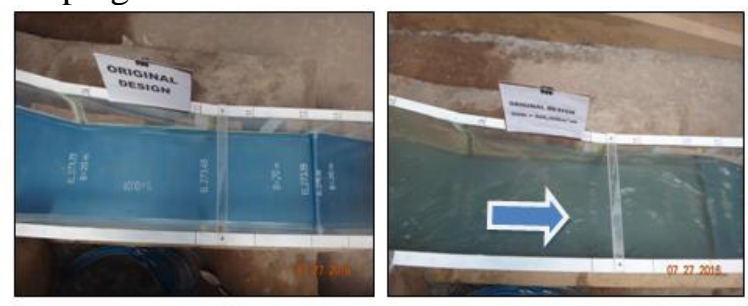

Gambar 7.Kondisi Saluran Transisi di Model Fisik Hidrolik.

\section{g. Saluran Peluncur (Chute Way)}

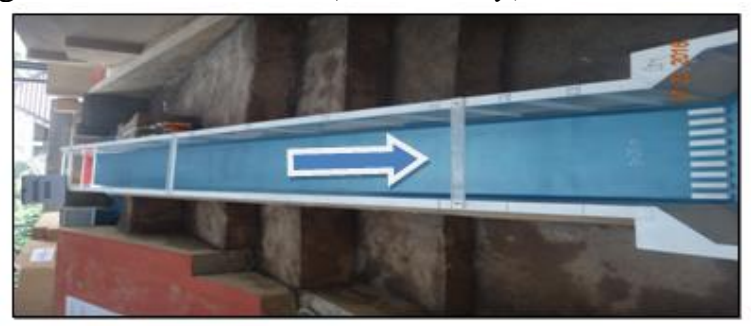

Gambar 8.Kondisi Saluran Peluncur di Model Fisik Hidrolik.
Secara umum kondisi aliran di saluran peluncur dalam kondisi baik dan sesuai persyaratan untuk menciptakan aliran super kritis yang nantinya akan diredam energinya di peredam energi (kolam olak).

\section{h. Peredam Energi (Energy Dissipator)}

Sebelum aliran air yang melintasi bangunan pelimpah dikembalikan lagi ke sungai, maka aliran dengan kecepatan tinggi (superkritis) tersebut harus diperlambat dan dirubah pada kondisi sub kritis. Dengan adanya chute block pada hilir saluran peluncur dapat mengurangi energi yang terdapat dalam aliran tersebut, namun belum dapat meredam energi yang terlalu besar, sehingga pada hilir peredam energi dimodifikasi dengan diletakkan sill dan dibuat kemiringan negatif berterap yang lebih tinggi sehingga diharapkan meningkatkan peredaman energi yang lebih baik.
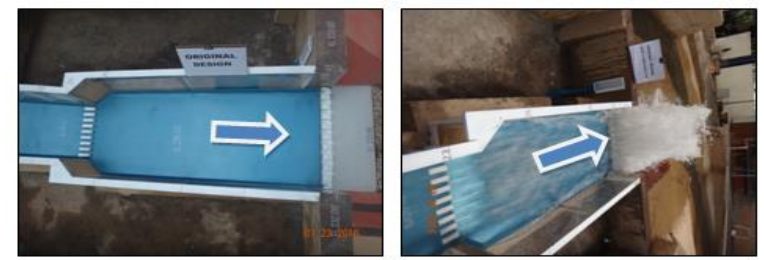

Gambar 9.Kondisi Peredam Energi di Model Fisik Hidrolik.

\section{i. Saluran Hilir (Escape Channel)}

Kondisi saluran di hilir peredam energi, terdapat tebing yang relatif tinggi dan beresiko terjadinya longsor. Oleh karena itu untuk keamanan, maka pada tebing kanan dan kiri diberi perlindungan agar apabila terdapat debit besar yang lewat tidak akan mudah terjadi longsor.

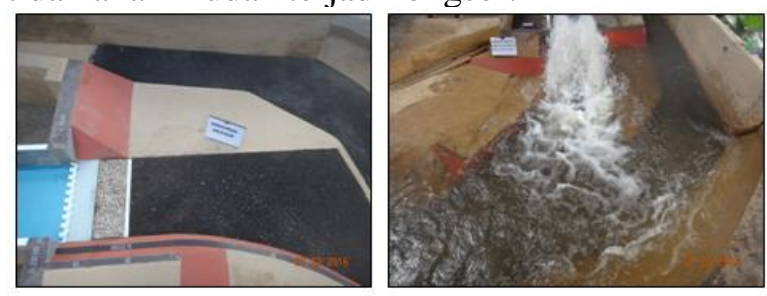

Gambar 10.Kondisi Saluran Hilir di Model Fisik Hidrolik.

\section{Model Final Design}

Berdasarkan perilaku aliran yang terjadi pada seri 0 yang telah dilakukan, maka dilakukan beberapa modifikasi pada bangunan model untuk 
mendapatkan perilaku aliran yang lebih baik secara hidrolik.

Modifikasi model dilakukan sebagai berikut:

1. Pelimpah dan Saluran Pengarah
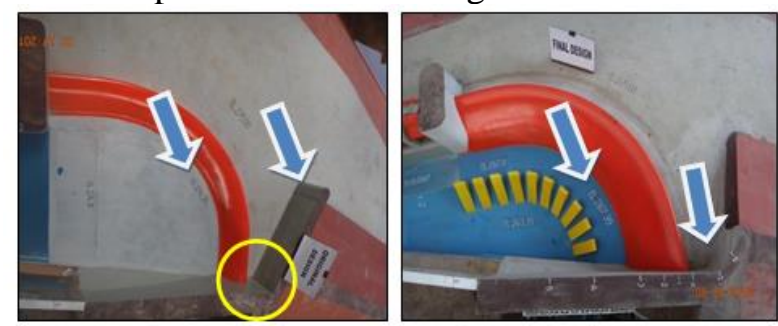

Gambar 11.Kondisi Hilir Pelimpah di Model Fisik Hidrolik

a. Perubahan elevasi pada hilir saluran pelimpah, diturunkan $7 \mathrm{~m}$, dari $+274,39 \mathrm{~m}$ menjadi $+267,39 \mathrm{~m}$ karena saluran pengatur tenggelam oleh aliran

b. Pada sudut ujung kiri pelimpah dibuat melengkung agar aliran air menuju pelimpah lebih halus dan tenang.

c. Pilar pada sebelah kiri pelimpah diperpendek hanya sampai puncak pelimpah darurat untuk menghindari terjadinya pusaran air.

\section{Saluran Samping}

Perubahan elevasi dasar pada hulu saluran samping, dasar saluran diturunkan $7 \mathrm{~m}$, dari $+274,31$ m menjadi $+267,31$ m karena mengikuti penurunan elevasi dari hilir pelimpah. Sedangkan pada hilirnya, dasar saluran diturunkan $7 \mathrm{~m}$, dari $+273,79$ m menjadi $+266,79$ m .

a. Pada saluran samping ini dipasang sill secara melengkung. Jarak pemasangan sill dari hilir pelimpah adalah $8 \mathrm{~m}$. Jarak antar sill yaitu 2 $\mathrm{m}$. Jumlah sill yang dipasang yaitu 10 buah. Pemasangan sill dibuat dengan kemiringan 1:2. Pemasangan sill ini bertujuan untuk meredam pusaran aliran yang terjadi pada hilir pelimpah yang apabila terjadi terus menerus, maka akan merusak dinding samping yang berada di depan hilir pelimpah samping. Oleh karena itu, selain dilakukan penurunan dasar juga diperlukan peredam energi pada dasar hilir pelimpah.

b. Kemiringan, panjang, serta lebar saluran samping di buat tetap yaitu kemiringan 0,0087, panjangnya $60 \mathrm{~m}$, serta lebar $30 \mathrm{~m}$ pada hulu, 20 pada hilir.
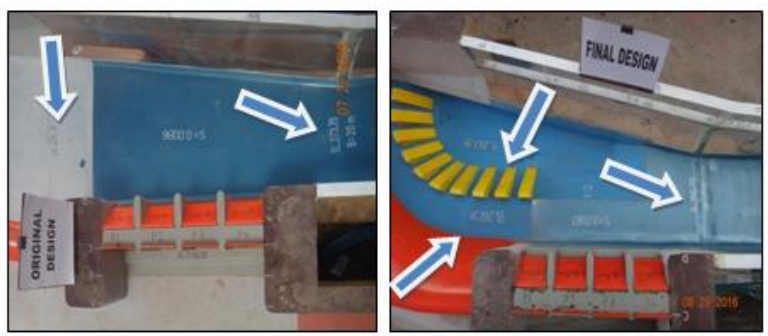

Gambar 12. Kondisi Saluran Samping di Model Fisik Hidrolik.

\section{Saluran Transisi}

a. Perubahan elevasi pada hulu saluran transisi I, dasar saluran diturunkan $7 \mathrm{~m}$, dari $+273,79 \mathrm{~m}$ menjadi $+266,79 \mathrm{~m}$. Sedangkan pada hilir saluran transisi I, dasar saluran diturunkan $7 \mathrm{~m}$, dari $+273,49$ m menjadi $+266,49$ m .

b. Perubahan elevasi pada hulu saluran transisi II, dasar saluran diturunkan $7 \mathrm{~m}$, dari $+273,49 \mathrm{~m}$ menjadi $+266,49 \mathrm{~m}$. Sedangkan pada hilir saluran transisi II yang awalnya $+273,19$ m diturunkan 7 $\mathrm{m}$, menjadi $+266,19 \mathrm{~m}$. Tinggi endsill Tinggi endsill diubah dari $2 \mathrm{~m}$ menjadi $2,5 \mathrm{~m}$ sehingga elevasi menjadi $+268,69 \mathrm{~m}$.

c. Pemasangan endsill pada saluran transisi II ini, dikarenakan pada saluran transisi ini terjadi aliran yang cepat dan tidak tercipta aliran tenang disepanjang saluran samping sampai saluran transisi hilir.
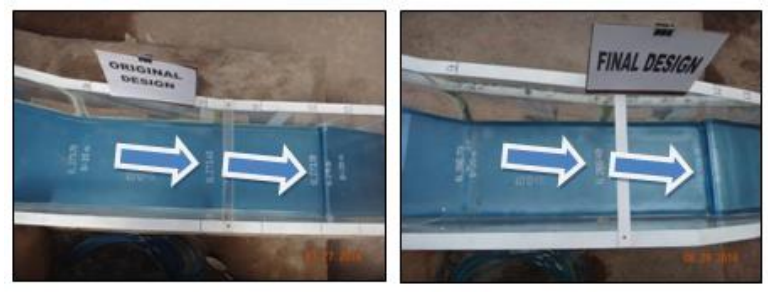

Gambar 13. Kondisi Saluran Transisi di Model Fisik Hidrolik

\section{Saluran Peluncur}

a. Saluran peluncur (chute way) dengan ujung hulu semula dengan elevasi $+273,19$ m serta ujung hilir $+218,00 \mathrm{~m}$ diturunkan $7 \mathrm{~m}$, menjadi: elevasi hulu $+266,19 \mathrm{~m}$ dan hilir $+206,00 \mathrm{~m}$.

b. Panjang saluran peluncur dibuat tetap yaitu $150 \mathrm{~m}$ sehingga kemiringannya berubah dari 0,3679 menjadi 0,4013 .

c. Pada ujung hilir saluran peluncur tetap diberi chute block dengan tinggi $1 \mathrm{~m}$, lebar $3,5 \mathrm{~m}$, 10 buah chute block. Pemberian chute block 
pada ujung saluran luncur berguna untuk mengurangi energi dalam aliran sebelum aliran tersebut menuju kolam olak, sehingga mampu menciptakan aliran subkritis pada kolam olak.
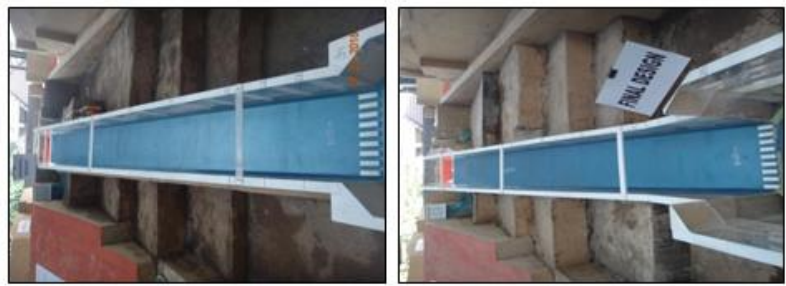

Gambar 14. Kondisi Saluran Peluncur di Model Fisik Hidrolik.

\section{Peredam Energi}

a. Untuk meredam aliran setelah melewati saluran peluncur, perlu adanya suatu peredaman agar aliran yang masuk ke saluran pengarah hilir kembali lagi ke kondisi subkritis, dipilih tipe peredam energi USBR Type II.

b. Perubahan elevasi pada kolam olak yang awalnya $+218,00 \mathrm{~m}$ diturunkan $12 \mathrm{~m}$, menjadi $+206,00 \mathrm{~m}$. Dimensi kolam olak tetap, lebar $30 \mathrm{~m}$ dan panjang $72 \mathrm{~m}$. Pada ujung hilir kolam olak tetap ada sill dengan tinggi $2,5 \mathrm{~m}$.
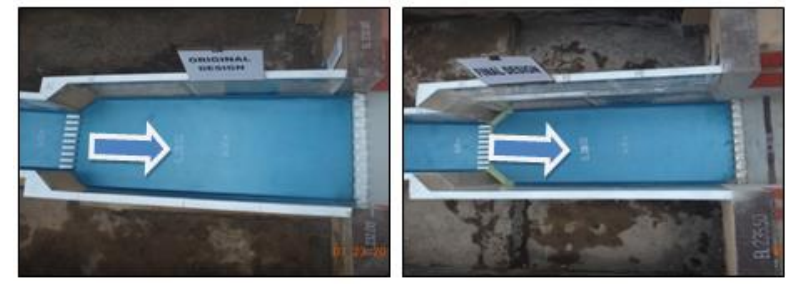

Gambar 15. Kondisi Peredam Energi di Model Fisik Hidrolik.

\section{Saluran Escape Channel}

Pada original design, escape channel sebelah kiri tidak memiliki dinding pelindung. Oleh karena itu, untuk keamanan maka pada tebing kanan diberi perlindungan agar apabila terdapat debit besar yang lewat tidak akan mudah terjadi longsor.

Bentuk dinding sebelah kanan dan kiri di buat sama, yaitu trapesium ganda Talud trapesium pertama pada elevasi $+227,00 \mathrm{~m}$ sedangkan Talud trapesium kedua pada elevasi $+232,00$ m dengan panjang 33,5 $\mathrm{m}$.

a. Pada tepat dihilir kolam olak, ditambahkan sill dengan kemiringan negatif dengan elevasi $+222,00 \mathrm{~m}$ diubah menjadi kemiringan negative berganda, kemiringan negative pertama 1:1 pada elevasi + $212,00 \mathrm{~m}$. Kemiringan negatif kedua dengan kemiringan 1:2 pada elevasi $+217,00 \mathrm{~m}$.

b. Pada hilir slope negatif terdapat groundsill pada saluran escape channel dengan panjang $5 \mathrm{~m}$ diubah menjadi panjangnya $30 \mathrm{~m}$. Ujung hilir gravel dinaikkan elevasi dasarnya, dari elevasi $+220,00 \mathrm{~m}$ menjadi $+215,50 \mathrm{~m}$.

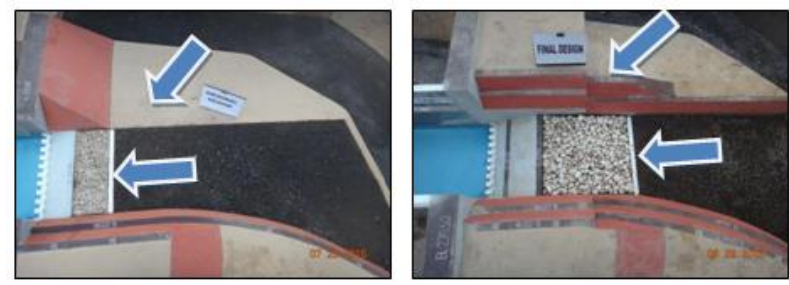

Gambar 16. Kondisi Saluranescape channel di Model Fisik Hidrolik.

7. Pintu

a. Ujung pilar hulu diubah menjadi bentuk rounded.

b. Pintu Radial dengan lebar pintu tetap $6 \mathrm{~m}$ dengan elevasi dasar pintu $+276,00 \mathrm{~m}$ dan elevasi ujung atas pintu yaitu 285,00 m. Lebar keseluruhan pintu tetap 43,35 m.
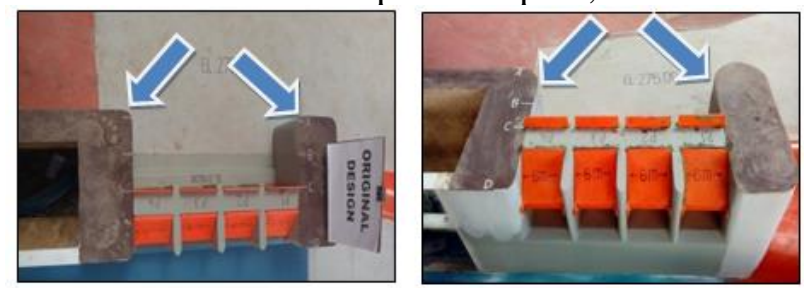

Gambar 17. Kondisi Pintu di Model Fisik Hidrolik.

\section{Analisa Hidrolika}

Bangunan pelimpah samping (side spillway) adalah suatu bangunan pelimpah yang saluran peluncurnya berposisi menyamping terhadap saluran pengatur aliran di hulunya (Sosrodarsono, 1989), (Kementerian PU, 1986).

Aliran yang melintasi bangunan pelimpah samping tersebut, seolah-olah terbagi menjadi dua tingkatan dengan dua buah peredam energi, yaitu yang pertama terletak pada bagian akhir saluran pengatur yang disebut saluran samping dan yang kedua adalah peredam energi di bagian akhir dari bangunan pelimpah tersebut.

Persyaratan yang perlu diperhatikan pada bangunan pelimpah tipe ini adalah agar debit 
banjir yang melintasinya, tidak menyebabkan aliran yang menenggelamkan bendung (submerged flow) pada saluran pengatur, maka saluran samping dibuat cukup rendah terhadap bendung tersebut.

Untuk dapat memenuhi persyaratan tersebut, maka bangunan pelimpah direncanakan sedemikian rupa, agar pada saat mengalirkan debit banjir abnormal, perbedaan elevasi permukaan air di hulu dan di hilir bendung pengatur tidak kurang dari $2 / 3$ kali tinggi air di atas mercu bendung tersebut (Sosrodarsono, 1989). Untuk analisa hidrolika pada pelimpah digunakan persamaan kontinuitas yaitu (Chow, 1989):

$Q=A_{1} \cdot V_{l}=A_{2} \cdot V_{2}$

dengan:

$\mathrm{Q}=$ Debit (m3/detik)

A1 = Luas daerah bidang-1 (m2)

$\mathrm{V} 1$ = Kecepatan air pada bidang-1 (m/det)

A2 = Luas daerah bidang $-2(\mathrm{~m} 2)$

$\mathrm{V} 2$ = Kecepatan air pada bidang-2 (m/det)
Sedangkan pada saluran transisi dan saluran peluncur, digunakan persamaan energi dengan metode perhitungan tahapan standar (Raju, 1986):

$h_{e}+\frac{v_{e}{ }^{2}}{2 g}=h_{c}+\frac{v_{c}{ }^{2}}{2 g}+\frac{K\left[v_{e}{ }^{2}-v_{c}{ }^{2}\right]}{2 g}+h_{m}$

dengan:

he $=$ Kedalaman aliran masuk ke dalam saluran transisi (m)

ve $=$ Kecepatan aliran masuk ke dalam saluran transisi (m/det)

$\mathrm{hc}=$ Kedalaman kritis pada ujung hilir saluran transisi (m)

$\mathrm{vc}=$ Kecepatan aliran kritis pada ujung hilir saluran transisi (m/det)

$\mathrm{K}=$ Koefisien kehilangan tinggi tekanan yang disebabkan oleh perubahan penampang lintang saluran transisi

$\mathrm{Hm}=$ Kehilangan total tinggi tekanan yang disebabkan oleh gesekan dan lain-lain.

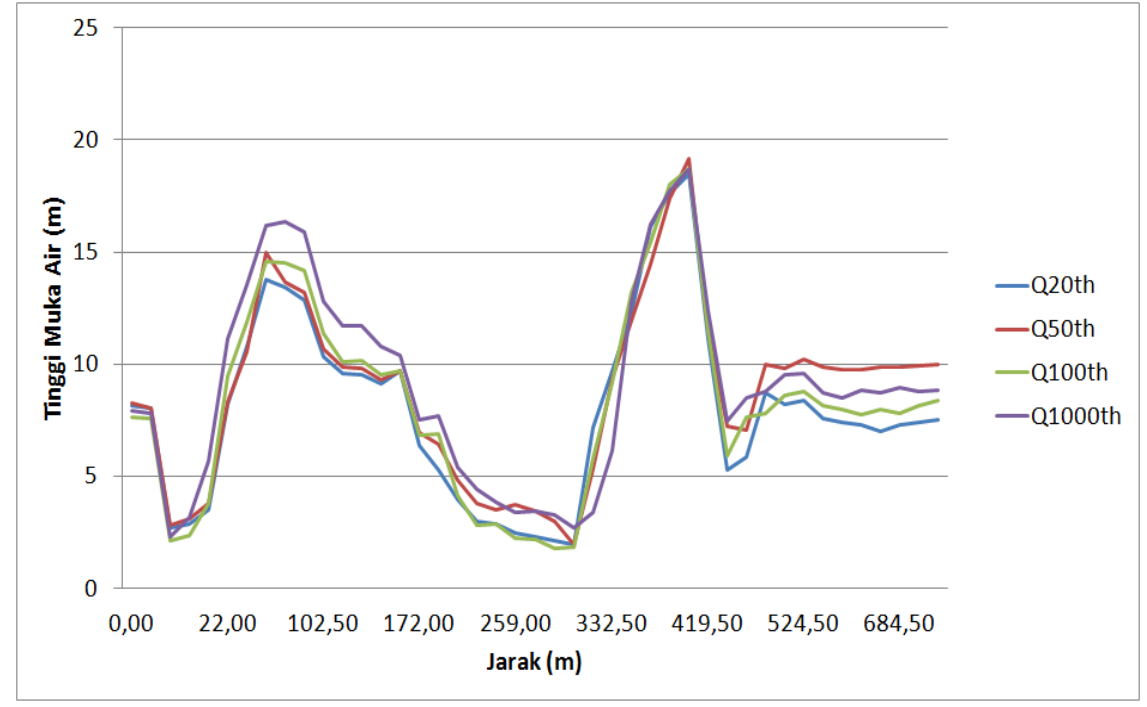

Gambar 18. Kondisi Aliran di Model Fisik Hidrolik

Pada daerah hilir, analisa hidrolika pelimpah menggunakan persamaan momentum (Raju, 1986):

$$
P_{1}-P_{2}-W \sin \theta-F a-F f=\beta_{\rho b}\left(V_{2}-V_{1}\right)(3)
$$

dengan:
$\mathrm{P} 1=$ tekanan pada section $1(\mathrm{kN} / \mathrm{m})$

P2 = tekanan pada section $2(\mathrm{kN} / \mathrm{m})$

$\mathrm{W}=$ berat air $(\mathrm{kN} / \mathrm{m})$

$\mathrm{Fa}=$ gesekan akibat tekanan atsmosfer $(\mathrm{kN} / \mathrm{m})$

Ff $=$ gesekan akibat dasar saluran $(\mathrm{kN} / \mathrm{m})$

$\beta=$ koefisien momentum 
V1 = kecepatan pada section $1(\mathrm{~m} / \mathrm{det})$

V2 = kecepatan pada section $2(\mathrm{~m} / \mathrm{det})$

B = lebar saluarn $(\mathrm{m})$

$=$ kerapatan $\left(\mathrm{kg} / \mathrm{m}^{3}\right)$

Pada Gambar 18 di atas menggambarkan profil muka air dari saluran pengarah hulu sampai dengan hilir sungai yang mewakili debit dengan kala ulang tertentu yaitu Q20, Q50, Q100, dan Q1000 final design. Dengan beberapa perubahan pada desain sebelumnya, maka kondisi aliran yang melalui pelimpah sudah dalam kondisi yang baik dan merata.

Aliran superkritis yang melewati saluran peluncur sudah diredam dengan sangat baik menjadi aliran subkritis pada peredam energi sehingga kondisi hilir pelimpah aman terhadap bahaya gerusan. Gambar 19 menunjukkan nilai bilangan Froude $(\mathrm{F})$ pelimpah dengan $\mathrm{F}>1$ terjadi di saluran peluncur dan $\mathrm{F}<1$ di peredam energi dan hilir sungai.

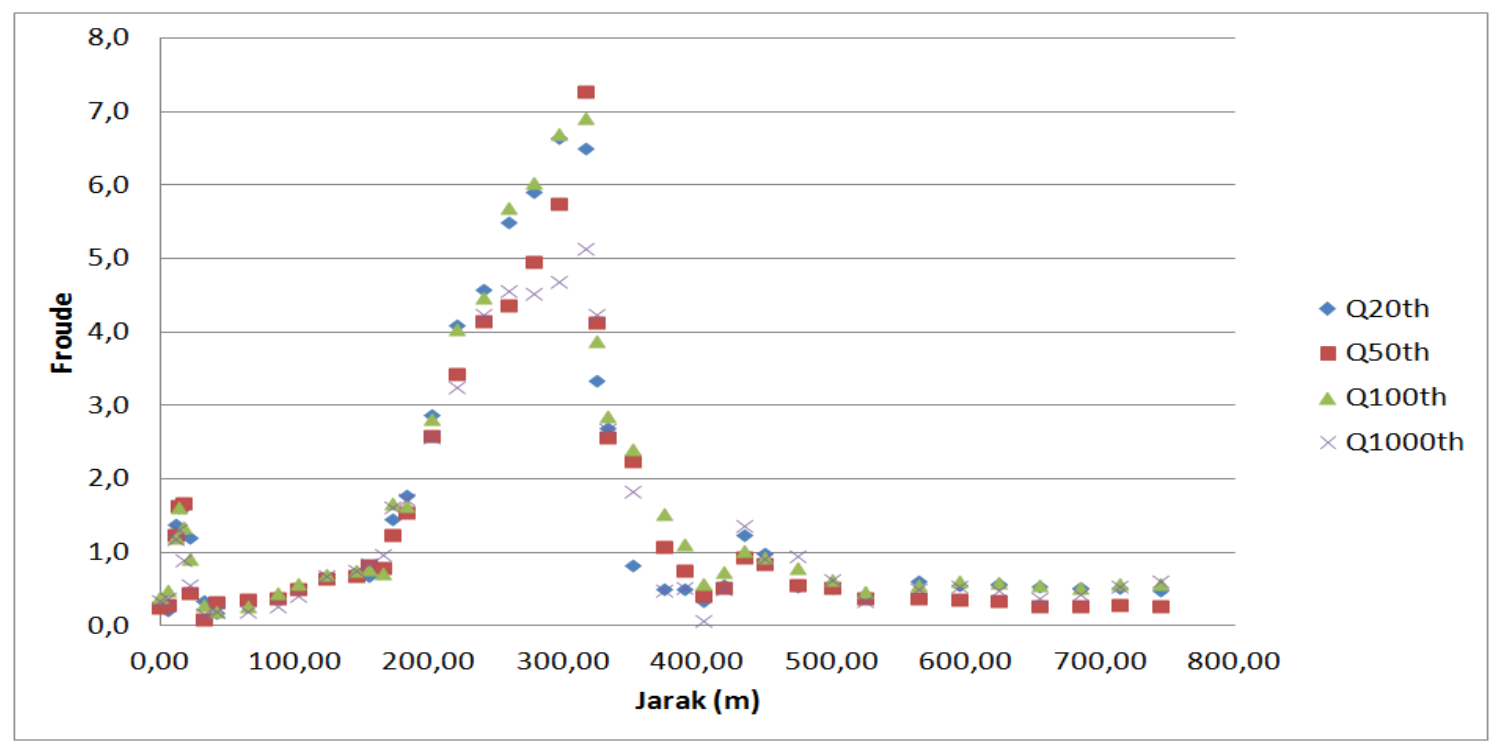

Gambar 19. Bilangan Froude pada Pelimpah Saka Gilas

\section{Aliran Getar}

Pada suatu saluran peluncur yang panjang terdapat bahaya ketidak stabilan dalam aliran yang disebut sebagai aliran getar (slug/pulsating flow). Apabila pa-njang saluran tersebut lebih dari 30 meter, maka harus dikontrol dengan cara menghitung bilangan Vendernikov(V) dan bilangan Montuori (M) (Anonim, 1986:95).

Bilangan Vendernikov (V):

$$
\underline{V}=\frac{2 b V}{3 P \sqrt{g h \cos \theta}}
$$

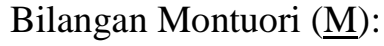

$$
\underline{M}^{2}=\frac{V^{2}}{g I L \cos \theta}
$$

dengan:

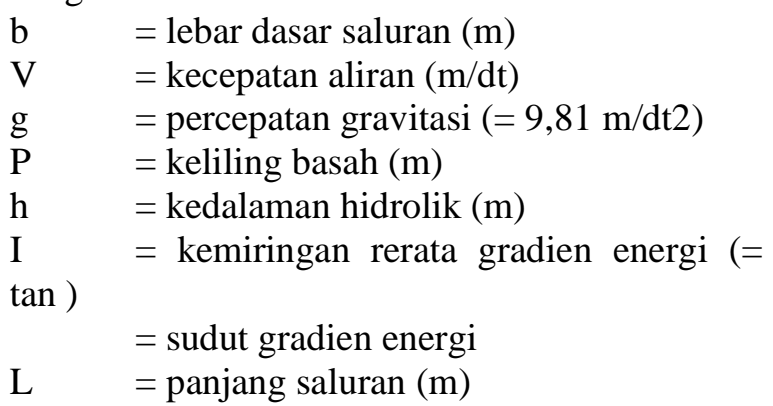

Berdasarkan hasil final design, baik dari debit dengan kala ulang terkecil sampai terbesar tidak menunjukkan adanya aliran getar pada pelimpah Saka Gilas seperti ditunjukkan pada Gambar 20. Pada semua debit percobaan, nilai bilangan Montuori dan bilangan Vendernikov berada pada daerah tanpa aliran getar. 


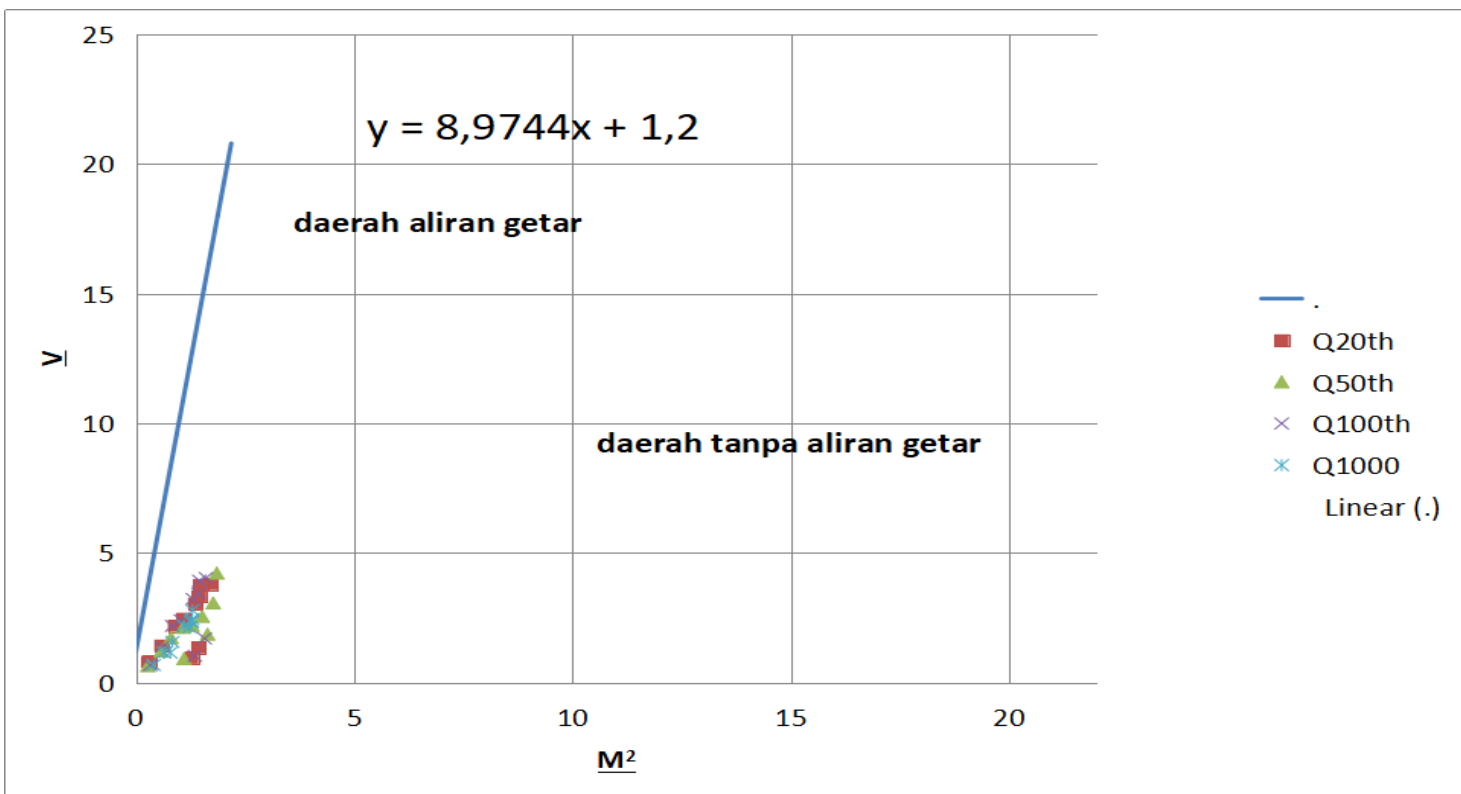

Gambar 20. Kondisi Aliran Getar pada Pelimpah Saka Gilas

\section{KESIMPULAN}

Hasil uji model fisik hidrolik kondisi original design yang telah dilakukan, menunjukkan bahwa masih banyak bagian saluran dari seluruh sistem pelimpah yang mempunyai kondisi hidrolika aliran yang kurang baik.

Modifikasi desain dilakukan untuk memperbaiki unjuk kerja hidrolika bangunan yang diujikan. Hasil modifikasi yang terakhir (final design) adalah modifikasi desain dengan hasil kinerja hidrolik terbaik.

Beberapa perubahan atau modifikasi yang dilakukan pada model original design ke model final design setelah dilakukan uji model fisik:

a. Kemiringan hilir saluran pelimpah dibuat tetap 1:0,8. Elevasi hilir dasar saluran pelimpah diturunkan $7 \mathrm{~m}$ supaya saluran pengatur tidak tenggelam oleh aliran.Elevasi pada hulu saluran samping diturunkan $7 \mathrm{~m}$ untuk memberikan perilaku hidrolika aliran yang jauh lebih baik.

b. Elevasi pada hulu saluran transisi I, diturunkan juga dasar salurannya sedalam 7 $\mathrm{m}$.

c. Penurunan elevasi dasar pada hulu saluran transisi II sebesar $7 \mathrm{~m}$. d. Penurunan elevasi dasar hilir saluran transisi II sedalam $7 \mathrm{~m}$. Peningkatan tinggi endsill dari $2 \mathrm{~m}$ menjadi $2,5 \mathrm{~m}$.

e. Penurunan dasar kolam olak sedalam $12 \mathrm{~m}$. Lebar dan panjang kolam olak tetap yaitu lebar $30 \mathrm{~m}$ dan panjang $72 \mathrm{~m}$. Pada ujung hilir kolam olak tetap ada sill dengan tinggi 2,5 m.

f. Pada debit rancangan Q2, Q50, Q100 dan Q1000 kavitasi tidak terjadi, sehingga saluran peluncur aman terhadap bahaya penggerusan lantai dasar akibat adanya tekanan negatif yang terjadi. Dasar penentuan adalah pada hasil analisa angka batas kavitasi. Nilai kavitasi selalu lebih besar dari angka batas kavitasi, sehingga dengan demikian saluran tersebut aman terhadap kavitasi (Patty, 1995).

g. Pada debit rancangan Q2, Q50, Q100 dan Q1000 aliran getar tidak terjadi. Aliran getar dari semua debit pengaliran masih dalam kondisi aman. Sehingga model dan prototipe aman terhadap aliran getar.

\section{DAFTAR PUSTAKA}

Bureau of Reclamation. 1987. Design of Small Dams. Oxford \& IBH Publishing CO. New Delhi Bombay Calcutta.

Chow, Ven Te, 1989. Hidrolika Saluran Terbuka, Alih Bahasa E.V. Nensi Rosalina, Penerbit Erlangga Jakarta. 
Kementerian PU, 1986. Buku Petunjuk Perencanaan Irigasi, Bagian Penunjang Untuk Standar Perencanaan Irigasi. Jakarta: Departemen Pekerjaan Umum.

Patty, O.F. 1995. Tenaga Air. Surabaya: Erlangga.

Raju, K.G.R. 1986. Aliran Melalui Saluran Terbuka, terjemahan Yan Piter
Pangaribuan B.E., M.Eng. Jakarta: Erlangga.

Sosrodarsono, Suyono dan Takeda, Kensaku. 1989. Bendungan Type Urugan. Jakarta: Erlangga.

Triatmojo, Bambang, 1995. Hidraulika II, Beta Offset, Yogyakarta. 